\title{
Establishment and Characterization of Novel Porcine Induced Pluripotent Stem Cells Expressing hrGFP
}

\author{
${ }^{1}$ Division of Physiology, Livestock Research Institute, Council of Agriculture, Executive Yuan, Tainan, 71246, Taiwan \\ ${ }^{2}$ Department of Medical Research, Buddhist Tzu Chi General Hospital, Hualien, 97004, Taiwan \\ ${ }^{3}$ Graduate Institute of Veterinary Pathobiology, National Chung Hsing University, Taichung, 40227, Taiwan \\ ${ }^{4}$ Department of Oral Medicine, National Cheng Kung University Hospital, Tainan, 70101, Taiwan \\ 5 Institute of Oral Medicine, College of Medicine, National Cheng Kung University, Tainan, 70101, Taiwan \\ ${ }^{6}$ School of Dentistry, College of Oral Medicine, Taipei Medical University, Taipei, 11031, Taiwan \\ ${ }^{7}$ Institute of Biotechnology, National Cheng Kung University, Tainan, 70101, Taiwan \\ ${ }^{8}$ Institute of Biotechnology, Southern Taiwan University, Tainan, 71005, Taiwan
}

Yu-Jing Liao', Chia-Hsin Liao', Jiunn-Wang Liao ${ }^{3}$, Kuo Yuan ${ }^{4,5,6}$, Yu-Zhan Liu', Yi-Shiou Chen', Lih-Ren Chen ${ }^{1,7,8}$ and Jenn-Rong Yang ${ }^{1, \star}$

\begin{abstract}
Induced pluripotent stem (iPS) cells have been established in various animal species since 2006. The pig is a potentially useful model in human regenerative medicine, and the characters of porcine embryonic stem (pES) cells were much similar with human embryonic stem (hES) cells. In present study, the traceable humanized recombinant green fluorescent protein expressing porcine induced pluripotent stem (piPS/hrGFP ${ }^{+}$) cells were generated from porcine ear fibroblasts (pEF) by introducing four human transcription factors (Sox2, Oct4, Klf4, and c-Myc) constructed in lentivirus vectors. The piPS/hrGFP+ ${ }^{+}$cells expressed hrGFP signal continuously and steadily for more than 90 passages. They also retained the typical defined characteristics including continuous proliferation with undifferentiated status, expression of ES pluripotency markers (Oct4, AP, SSEA-3, SSEA-4, TRA-1-60, and TRA-1-81), and maintenance of a normal karyotype $(36+X Y)$. Three embryonic germ layers were also successfully revealed from in vitro differentiation by embryonic body (EB) formation. Various histological analysis and immunohistochemical staining of the teratomas revealed various tissues derived from three embryonic germ layers, including neural tissues, keratin-containing epidermal tissues, skeletal muscle, smooth muscle, cartilage, adipose tissues, and glandular structures. These results support that piPS/hrGFP+ cells can be generated from pEF by direct reprogramming, and these traceable piPS/hrGFP cells would be beneficial for future application on cell transplantation and tissue regeneration.
\end{abstract}

Keywords: Porcine; Ear fibroblasts (EF); Induced pluripotent stem (iPS) cells; Humanized recombinant green fluorescent protein (hrGFP)

\section{Introduction}

Embryonic stem (ES) cells derived from the inner cell mass of the blastocyst were first established from mouse, and they could grow indefinitely with pluripotency and differentiate into all three embryonic germ layers [1]. ES cells, however, face ethical controversies because they derived from blastocysts. Fortunately, induced pluripotent stem (iPS) cells derived from somatic cells, which believed to possess similar ability as ES cells, were established in 2006 by direct reprogramming [2]. By using this technique, we could establish pluripotent cell lines easily and circumvent ethical problems.

The pig, a common livestock species, has the potential to serve as a great research model for human biomedicine, and has been considered an optimal model for preclinical development of therapeutic approaches because the organ size, immunology, and whole animal physiology are similar to human [3-5]. Porcine embryonic stem (pES) cells, like human embryonic stem (hES) cells, were maintained on the feeder layer without supplement of leukemia inhibitory factor (LIF) [6]. Also, the pES cells shares similar colony morphology, and expressed the same pluripotency markers including Oct4, AP, SSEA-3, SSEA-4, TRA-1-60, and TRA-1-81, but not SSEA-1 which is characterized to mouse ES cells $[7,8]$. Therefore the pig is a potentially useful model in human regenerative medicine.

In our previous studies, we successfully established pES cells expressing humanized recombinant green fluorescent protein (pES/
$\mathrm{hrGFP}^{+}$cells) [8]. These cells ameliorated the Parkinson's disease and spinal cord injury in the rat models by xenotransplantation $[9,10]$, and also the periodontal furcation defects in a porcine model by allotransplantation [11]. In present study, porcine induced pluripotent stem cells expressing hrGFP ( $\mathrm{piPS} / \mathrm{hrGFP}^{+}$) were generated from porcine ear fibroblasts ( $\mathrm{pEF}$ ) by introducing four human transcription factors (Oct4, Sox2, Klf4, and c-Myc) constructed in lentivirus vectors, and the common criteria for iPS cells were investigated. The main goal for present study was to pave the way for transplantation study, especially allotransplantation. By detecting hrGFP expression, we could easily monitor the growth, differentiation, and migration of grafted cells. In, addition, we expect that $\mathrm{piPS} / \mathrm{hrGFP}^{+}$cells not only could be used as cell resources to study the Parkinson's disease, spinal cord injury, and periodontal furcation defects, but also have the potential for future therapeutic application on regenerative medicine by allotransplantation.

*Corresponding author: Jenn-Rong Yang PhD, Physiology Division, Livestock Research Institute, Council of Agriculture, Executive Yuan, Tainan, Taiwan. 112 Farm Rd., Hsinhua, Tainan, 71246, Taiwan, Tel: +886-6-5911884; Fax: +886-65912581; E-mail: jryang@mail.tlri.gov.tw

Received April 11, 2014; Accepted May 14, 2014; Published May 16, 2014

Citation: Liao YJ, Liao CH, Liao JW, Yuan K, Liu YZ, et al. (2014) Establishment and Characterization of Novel Porcine Induced Pluripotent Stem Cells Expressing hrGFP. J Stem Cell Res Ther 4: 208. doi:10.4172/2157-7633.1000208

Copyright: ( 2014 Liao YJ, et al. This is an open-access article distributed under the terms of the Creative Commons Attribution License, which permits unrestricted use, distribution, and reproduction in any medium, provided the original author and source are credited. 


\section{Materials and Methods}

\section{Induction and culture of green fluorescent protein expressing porcine ear fibroblasts}

The pEF in this study was derived from the ear dissection of Livestock Research Institute Black Pig No. one (a topcrossing breed established from Taoyuan and Duroc pigs, No. 53501) and trypsinized to single cells by $0.25 \%(\mathrm{w} / \mathrm{v})$ trypsin- $0.02 \mathrm{mM}$ EDTA (Invitrogen, Grand Island, NY, USA). The pEF were maintained in Dulbecco's modified eagle medium (DMEM, high glucose and no pyruvate, Invitrogen) supplemented with $10 \%$ fetal bovine serum (FBS, Invitrogen) and 100 units $/ \mathrm{mL}$ penicillin-100 g/mL streptomycin (Sigma-Aldrich, St. Louis, $\mathrm{MO}, \mathrm{USA}$ ) at $37^{\circ} \mathrm{C}$ with an atmosphere of $5 \% \mathrm{CO}_{2}$ in air. The methods for induction of hrGFP by electroporation-mediated transfection were described in previous study [8]. Briefly, the pEF cells was trypsinized to single cells and adjusted to a concentration of approximately $5 \times 10^{4}$ cells/mL in phosphate buffered solution (PBS). Approximately $20 \mu \mathrm{g}$ of pAAV-hrGFP Control Plasmid (Stratagene, Santa Clara, CA, USA) were added into the cells suspension in the electroporation cuvette (Cuvettes PlusTM, Model No. 620, BTX, San Diego, CA, USA). Electroporation with condition including 2 DC pulses, $150 \mathrm{~V} / \mathrm{cm}$ of field strength, and $10 \mathrm{msec}$ duration time was performed by the Electro Cell Manipulator (BTX ECM 2001, San Diego, CA, USA). Approximately 40\% of pEF expressed hrGFP after electroporation. When the total cell number was scaled up to 15 million, the pEF were collected for hrGFP positive sorting by flow cytometer (FACSVantage SE, Becton, Dickinson and Company, Franklin Lakes, NJ, USA). We obtained more than $95 \%$ hrGFP expressing $\mathrm{pEF}$ and nominated as $\mathrm{pEF} / \mathrm{hrGFP}^{+}$cells.

\section{Induction and culture of hrGFP expressing porcine induced pluripotent cells}

For the generation of four factors-induced piPS cells, $\mathrm{pEF} / \mathrm{hrGFP}^{+}$ cells were cultured in Multidishes Nunclon"s ${ }^{\prime \prime}$ 6-wells (Nunc 140675, Roskilde, Denmark) to a cell number of 80,000/well and infected with human Oct4, Sox2, Klf4, and c-Myc constructed in lentivirus vectors (TLC-TRE-iPS-II, Tseng Hsiang Life Science LTD, Taipei, Taiwan). On day 2 after infection, the infection medium was withdrawn, and the cells were maintained in pES cells culture medium (ESM) at $37^{\circ} \mathrm{C}$ with an atmosphere of $5 \% \mathrm{CO}_{2}$ in air. The ESM consisted of DMEM supplemented with $1 \mathrm{mM} \mathrm{L}$-glutamine, $0.1 \mathrm{mM} \beta$-2-mercaptoethanol, $10 \mathrm{mM}$ MEM non-essential amino acids, $0.03 \mathrm{mM}$ adenosine, $0.03 \mathrm{mM}$ guanosine, $0.03 \mathrm{mM}$ cytidine, $0.03 \mathrm{mM}$ uridine, $0.01 \mathrm{mM}$ thymidine (all from Sigma-Aldrich), antibiotics (50 units/mL penicillin $\mathrm{G}$ and 50 $\mu \mathrm{g} / \mathrm{mL}$ streptomycin sulfate, Invitrogen) and $16 \%$ fetal bovine serum (FBS, Invitrogen) as described previously [12].

For isolation and establishment of piPS cells, the colonies exhibited dome-like morphology were picked up about 1 month post-infection. These cells were subsequently expanded and maintained in ESM on mitomycin C (Sigma-Aldrich) inactivated STO feeders (mouse embryonic fibroblasts, CRL-1503, ATCC, Manassas, VA, USA). These putative piPS/hrGFP+ ${ }^{+}$cells were regularly subcultured every 5 to 7 days.

\section{Characterization of the plurioptencyt markers}

The putative piPS/hrGFP ${ }^{+}$cells were fixed in $10 \%(\mathrm{v} / \mathrm{v})$ neutral buffered formalin for $30 \mathrm{~min}$, and permeabilized with $0.3 \%(\mathrm{v} / \mathrm{v})$ Triton X-100 for 10 min after washing with PBS three times. After permeabilization, the cells were incubated with blocking solution $[5 \%$ (v/v) FBS in PBS containing 0.1\% (v/v) Tween-20] for $2 \mathrm{~h}$ at room temperature, and then incubated with primary antibody diluted with blocking solution (1:200 dilution) at $4^{\circ} \mathrm{C}$ overnight. After washing with
PBS three times on the next morning, the cells were incubated with secondary antibody diluted with blocking solution (1:200 dilution) for $2 \mathrm{~h}$ at room temperature. The cells were then washed twice with PBS again, and stained with 4,6-diamidino-2-phenylindole (DAPI).

Primary antibodies used for determining the undifferentiated status of piPS/hrGFP cells were ES cell-specific markers, including Octamer-binding transcription factor-4 (Oct-4, Millipore Cat. \#AB3209, Temecula, CA, USA), alkaline phosphatase (AP, Millipore Cat. \#MAB4349), stage specific embryonic antigen-3 (SSEA-3, Millipore Cat. \#MAB4303), stage specific embryonic antigen-4 (SSEA4, Millipore Cat. \#MAB4304), tumor related antigen-1-60 (TRA-1-60, Millipore Cat. \#MAB4360), and tumor related antigen-1-81 (TRA1-81, Millipore Cat. \#MAB4381). The secondary antibodies were the rhodamine (TRITC)-conjugated AffiniPure goat anti-rabbit IgG $(\mathrm{H}+\mathrm{L})$ (for Oct-4 staining, Jackson ImmunoResearch Cat \#111-025-003, West Baltimore Pike, PA, USA), rabbit anti-mouse $\operatorname{IgG}(\mathrm{H}+\mathrm{L})$ (for AP and SSEA-4 staining, Jackson ImmunoResearch Cat. \#315-025-003), rabbit anti-rat IgM (for SSEA-3 staining, Jackson ImmunoResearch Cat. \#312025-020), and rabbit anti-mouse IgM+IgG (for TRA-1-60 and TRA-181 staining, Jackson ImmunoResearch Cat \#315-025-044). Fluorescent cells were visualized by the inverted fluorescent microscopy (DM IRB, Leica, Wetzlar, Germany) equipped with CCD camera (CoolSNAP ${ }_{\mathrm{HO} 2}$ Monochrome, Photometrics, Tucson, AZ, USA), and the images were analyzed by RS image software (Photomatrics).

\section{Karyotype analysis}

G-banding was used for karyotyping analysis and carried out as previously described $[8,13]$. Briefly, The piPS/hrGFP ${ }^{+}$cells were then mitotically arrested with colcemid (KaryoMax Colcemid solution, Invitrogen) at a final working concentration of $0.02 \mu \mathrm{g} / \mathrm{mL}$ at $39^{\circ} \mathrm{C}$ for $30 \mathrm{~min}$. Cells were harvested for hypotonic treatment for 30 min in $0.56 \%(\mathrm{w} / \mathrm{v}) \mathrm{KCl}$ aqueous solution following removal from colcemid treatment on dish (in situ method). The cells were pelleted by centrifugation at $800 \times \mathrm{g}$ and fixed in cold Carnoy's fixative $(3: 1, \mathrm{v} / \mathrm{v}$, of absolute methanol to glacial acetic acid) for $10 \mathrm{~min}$. After a second wash in Carnoy's fixative, the cells were resuspended in $2 \mathrm{~mL}$ fixative. Slides were prepared by dropping the cell suspension onto dry microscope slides prewashed with fixative. Immediately after dropping, the slides were exposed to a flame to burn off the fixative, incubated 30 seconds to 1 minute in a trypsin (1:250) solution $(0.1 \mathrm{~g}$ trypsin in $100 \mathrm{~mL}$ isotonic buffer), rinsed for a few seconds in a jar with FBS (2-3 mL FBS in 50 $\mathrm{mL}$ isotonic buffer), rinsed in isotonic buffer, and then stained in 5\% Gurr's Giemsa staining solution (Invitrogen) for $2 \mathrm{~min}$. The stained slides were rinsed, air dried and examined under a microscope at 1,000 $\times$ magnification with oil immersion. The images were then analyzed by Applied Images software (AI cytovision 2.8, 2002, Applied Images Group, Gainesville, GA, USA).

\section{Gene expression analysis}

For gene expression analysis of porcine endogenous Oct4 ( $p$ Oct4), Sox2 ( $p$ Sox2), Klf4 ( $p$ Klf4), and $c-M y c$ ( $p c-M y c)$, the total RNA of $\mathrm{pEF} / \mathrm{hrGFP}^{+}$, piPS/hrGFP ${ }^{+}$, and $\mathrm{pES} / \mathrm{hrGFP}^{+}$cells were extracted by PureLink ${ }^{\prime \prime}$ RNA Mini Kit (Ambion, Grand Island, NY, USA), and reverse-transcribed into cDNA by Transcriptor First Strand cDNA Synthesis Kit (Roche, Indianapolis, IN, USA). RT-PCR was performed on TPersonal RT-PCR system (Biometra GmbH, Rudolf-Wissell-Str. 30, D-37079 Goettingen, Germany). The conditions of RT-PCR were as follows: $94^{\circ} \mathrm{C}, 5 \mathrm{~min} / 94^{\circ} \mathrm{C}, 30 \mathrm{sec}$ for denaturation; $60^{\circ} \mathrm{C}, 30 \mathrm{sec}$ for annealing; $72^{\circ} \mathrm{C}, 1 \mathrm{~min} / 72^{\circ} \mathrm{C} 3 \mathrm{~min}$ for elongation; $4^{\circ} \mathrm{C}$ pause; followed by 32 amplification cycles. The primers used in the study were listed as Table 1 . 


\section{Embryoid body formation, differentiation, and embryonic germ layers determination}

For the formation of embryoid body (EB), piPS/hrGFP+ cells were removed from their feeders and subjected to suspending culture by hanging drops in the bacteriological Petri dish [8]. The piPS/hrGFP ${ }^{+}$ cells were harvested and cultured in $20 \mu \mathrm{L}$ of ESM on the lid of 100 $\mathrm{mm}$ sterile bacteriological Petri. The cells were cultured at $37^{\circ} \mathrm{C}$ with an atmosphere of $5 \% \mathrm{CO}_{2}$ in air for 7 days. The medium was regularly changed every other day. After 7 days culture, the formed EB was transferred to gelatin-coated 48 well in the same medium for another 14 days to induce in vitro spontaneous differentiation.

Immunocytochemical study was implemented for analysis of embryonic germ lineages of the differentiated EB. The EB was fixed and treated as mentioned above. The primary antibodies for determining ectodermal differentiation were specific against neurofilament light (NFL, Millipore Cat. \#AB9568), microtubule associated protein 2 (MAP2, Millipore Cat. \#MAB3418), and cytokeratin (Sigma Cat. \#C-2562). The primary antibody for determining mesodermal differentiation was specific against atrial natriuretic peptide (ANP, Millipore Cat. \#AB1970). The primary antibody for determining endodermal differentiation was specific against $\alpha$-fetoprotein (AFP, Santa Cruz Cat. \#SC-8108, Dallas, TX, USA). The secondary antibodies were the rhodamine (TRITC)-conjugated AffiniPure goat anti-rabbit $\operatorname{IgG}(\mathrm{H}+\mathrm{L})$ (for NFL and ANP staining, Jackson ImmunoResearch Cat \#111-025-003), rabbit anti-mouse IgG $(\mathrm{H}+\mathrm{L})$ (for MAP2 and cytokeratin staining, and rabbit anti-goat IgG $(\mathrm{H}+\mathrm{L})$ (for AFP staining, Jackson ImmunoResearch Cat \#305-025-003).

\section{Teratoma formation and in vivo tracking}

All animal experiments in this study were performed in accordance with ethical guidelines and following approval of the Livestock Research Institutional Animal Care and Use Committee (IACUC).

For teratoma formation analysis, five female nonobese diabetic/ severe combined immunodeficiency (NOD-SCID) mice (Bio-LASCO, Taiwan) at 8 weeks of age were anesthetized with Zoletil/Rompun mixture $(15 \mathrm{mg} / \mathrm{kg})$. The $\mathrm{piPS} / \mathrm{hrGFP}^{+}$cell suspension of $1 \times 10^{6}$ cells in $100 \mu \mathrm{L}$ ESM were injected subcutaneously into the left doral flank. Length, width, and height of teratoma were measured every 15 days after injection during the 3-month experimental period.

For in vivo monitoring of these grafted piPS/hrGFP ${ }^{+}$cells in NODSCID mice, live animal fluorescence optical imaging system, the In Vivo Imaging System (IVIS 50, Xenogen Corp., Alameda, CA, USA), was used for non-invasive tracking every 15 days during the 3-month experimental period. The relative fluorescence values of treatment groups were calculated as the fluorescence intensity detected from the region of interest (ROI) on mice in each treatment group divided by that of the control groups at the same time window.

\section{Histological analysis of teratoma}

Three months after the injection, teratomas were surgically dissected from the NOD-SCID mice. Samples were fixed in 10\% (v/v) neutral buffered formalin for 1 week, and embedded in paraffin after serial dehydration by alcohol. Samples were dissected at $3 \mu \mathrm{m}$ in thickness and stained with hematoxylin and eosin by standard procedure. For immunohistochemical staining, slides were deparaffinized and immersed in boil sodium citrate buffer ( $\mathrm{pH} 6.0)$ containing $0.05 \%(\mathrm{v} / \mathrm{v})$ Tween-20 for $15 \mathrm{~min}$ to retrieve the antigen. After cooling down at room temperature for $20 \mathrm{~min}$, slides were washed with PBS containing $0.1 \%$ $(\mathrm{v} / \mathrm{v})$ Tween-20 (PBS/Tween-20) three times and removed endogenous peroxidase by $3 \%(\mathrm{v} / \mathrm{v}) \mathrm{H}_{2} \mathrm{O}_{2}$ for 10 min. After washing with PBS/ Tween-20 three times, slides were blocked with blocking solution [5\% (v/v) FBS in PBS containing $0.1 \%(\mathrm{v} / \mathrm{v})$ Tween-20] for $1 \mathrm{~h}$ at room temperature, and then incubated with primary antibody diluted in blocking solution (1:150 dilution) for $1 \mathrm{~h}$ at room temperature. After washing with PBS/Tween-20 three times, slides were incubated with secondary antibody diluted in blocking solution (1:200 dilution) for $30 \mathrm{~min}$. Finally, slides were stained with 3,3'-Diaminobenzidine (DAB, Invitrogen, Grand Island, NY, USA) after washing with deionized and distilled water three times, and rinsed with $1 \%$ ammonia solution after counterstaining with hematoxylin.

The primary antibodies for determining embryonic germ layers in teratomas were specific against nestin (Millipore Cat. \#MAB5326), MAP2, cytokeratin, and cardiac troponin I (cTn I, Millipore Cat. \#AB1627). The secondary antibodies were Peroxidase-AffiniPure Goat Anti-Rabbit IgG $(\mathrm{H}+\mathrm{L})$ (for nestin, and cTn I staining, Jackson ImmunoResearch Cat \# 111-035-003) and Peroxidase-AffiniPure Rabbit Anti-Mouse IgG (H+L) (for MAP2 and cytokeratin staining, Jackson ImmunoResearch Cat \# 315-035-003).

\section{Statistical analyses}

All data were displayed as mean \pm SEM.

\section{Results}

\section{Generation of piPS/hrGFP+ cells}

The pEF derived from the ear fibroblasts were collected and cultured in DMEM supplemented with 10\% FBS after trypsinization (Figure 1A). Thereafter, the $\mathrm{pEF} / \mathrm{hrGFP}^{+}$cells were obtained by transfecting pEF with pAAV-hrGFP Control Plasmid using electroporation. (Figure 1B). The experimental schedule for $\mathrm{piPS} / \mathrm{hrGFP}^{+}$cells isolation was summarized in Figure 1C. The pEF/GFP ${ }^{+}$cells were further infected with human Oct4, Sox2, Klf4, and $c-M y c$ constructed in lentivirus vectors. On day 2 after infection, the infection medium was withdrawn, and the cells were maintained in ESM. The infected cells grew into round shape and aggregated approximately two weeks later (Figure 1D), and the typical dome-like morphology of ES colony appeared about day 30 after infection (Figure 1E). The dome-like colonies were further mechanically picked up and disaggregated into small clumps by continuous pipetting. The cell clumps were then plated onto mitomycin C inactivated STO feeder layers and subsequently flatten into typical undifferentiated pES colony morphology (Figure 1F). These colonies induced from $\mathrm{pEF} / \mathrm{hrGFP}^{+}$cells also successfully expressed hrGFP and were named as piPS/hrGFP+ cells (Figure 1G).

\section{Expression of ES cell pluripotentcy markers}

To investigate the expression of pluripotency markers of piPS/

\begin{tabular}{|c|c|c|c|}
\hline Gene & \multicolumn{1}{|c|}{ Sequences } & $\begin{array}{c}\text { Length } \\
(\mathrm{bp})\end{array}$ & $\begin{array}{c}\text { Annealing } \\
\left({ }^{\circ} \mathrm{C}\right)\end{array}$ \\
\hline pOct4 & $\begin{array}{c}\text { F: 5'-AGGTGTTCAGCCAAACGACC-3' } \\
\text { R: 5'-TGATCGTTTGCCCTTCTGGC-3' }\end{array}$ & 335 & 60 \\
\hline pSox2 & $\begin{array}{c}\text { F: 5'-GCAACTCTACTGCTGCGGCG-3' } \\
\text { R: 5'-GCCATGCTGTTGCCTCC-3' }\end{array}$ & 352 & 60 \\
\hline pKIf4 & $\begin{array}{l}\text { F: 5'-GCGGAGGAACTGCTAAG-3' } \\
\text { R: 5'-GCACTTCTGGCACTGGA-3' }\end{array}$ & 423 & 60 \\
\hline pc-Myc & $\begin{array}{l}\text { F: 5'-TCGGACTCTCTGCTCTCCTC-3' } \\
\text { R: 5'-CTGCATAATTGTGCTGGTGC-3' }\end{array}$ & 274 & 60 \\
\hline Actin & $\begin{array}{c}\text { F: 5'-CTCCTTAATGTCACGCACGATTTC-3' } \\
\text { R: 5'-GTGGGGCGCCCCAGGCACCA-3' }\end{array}$ & 539 & 60 \\
\hline
\end{tabular}

Table 1: Primer sets for RT-PCR. 
Citation: Liao YJ, Liao CH, Liao JW, Yuan K, Liu YZ, et al. (2014) Establishment and Characterization of Novel Porcine Induced Pluripotent Stem Cells Expressing hrGFP. J Stem Cell Res Ther 4: 208. doi:10.4172/2157-7633.1000208

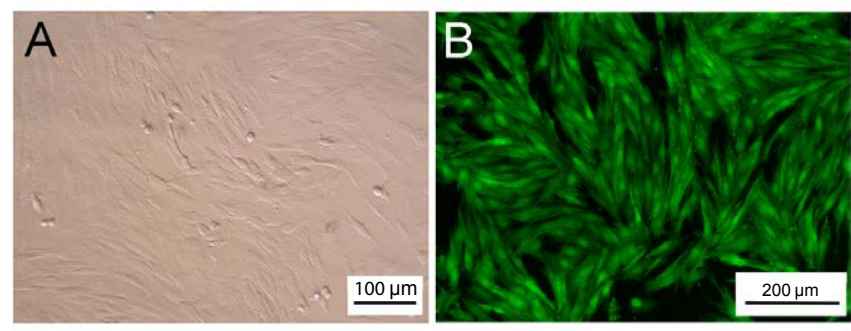

C
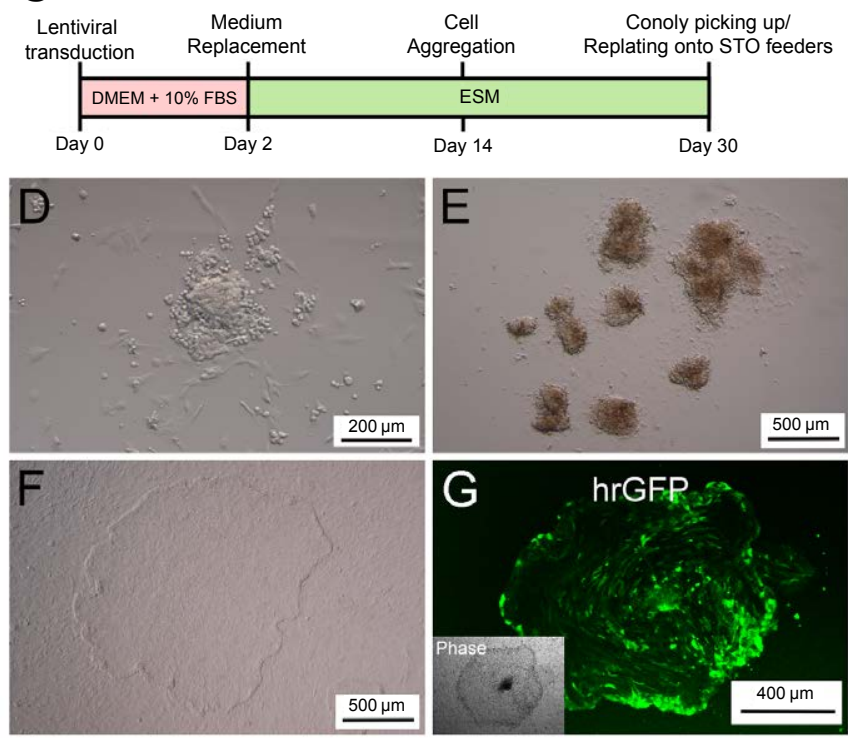

Figure 1: Induction of piPS/hrGFP+ cells from pEF. (A) Morphology of $p E F$ cells. (B) hrGFP expression of pEF/hrGFP ${ }^{+}$Cells. (C) Time schedule of piPS/ $\mathrm{hrGFP}^{+}$cell generation. (D) Aggregation of reprogrammed $\mathrm{pEF} / \mathrm{hrGFP}^{+}$cells. (E) Typical image of ES dome-like colony of reprogrammed $\mathrm{pEF} / \mathrm{hrGFP}^{+}$cells. (F) Typical image of piPS/hrGFP ${ }^{+}$colony. (G) hrGFP expression of piPS/ hrGFP ${ }^{+}$colony.

$\mathrm{hrGFP}^{+}$cells, ES cell-specific surface antigens including Oct4, AP, SSEA-3, SSEA-4, TRA-1-60, and TRA-1-81 were determined. The results of immunocytochemical study showed that the piPS/hrGFP ${ }^{+}$ cells were positive for those pluripotency markers (Figure 2A). The expression of endogenous pluripotency genes ( $p$ Oct4, pSox 2, pKlf-4, and $p c-M y c$ ) were also detected in piPS/hrGFP ${ }^{+}$and $\mathrm{pES} / \mathrm{hrGFP}^{+}$cells. In addition, $p K l f-4$ and $p c-M y c$ were prominently expressed in the $\mathrm{pEF} /$ $\mathrm{GFP}^{+}$cells (Figure 2B).

\section{Karyotype analysis}

Karyotyping of the piPS/hrGFP ${ }^{+}$cells was performed by G-banding staining for monitoring of their chromosomal normality. The results indicated that the piPS/hrGFP ${ }^{+}$cells maintained in culture for more than 90 passages possessed a normal $36+$ XY male karyotype (Figure $3)$.

\section{In vitro differentiation}

The piPS/hrGFP ${ }^{+}$cells formed ball-shaped EB (Figure 4A) and retained hrGFP signal after 7 days of hanging drops culture (Figure 4B). The EB formation rate was about $93.6 \pm 4.7 \%(190 / 203, \mathrm{n}=10)$. Spontaneous differentiation of $\mathrm{piPS} / \mathrm{hrGFP}^{+}$cells was evident when the EBs allowed to grow in gelatin-coated surface. On day 3-5 after adherent culture, the EB in ESM attached to the surface of gelatin- coated 48 well (Figure 4C) and began to differentiate into cells of three embryonic germ layers. The attached cells exhibited various types of morphologies, but the morphology of cells changed frequently. The differentiation timing of each embryonic germ layer was various. Generally, neuron-like cells with obvious Nissl body first appeared on day 3 after successful attachment (Figure 4D), and that gradually differentiated into epithelial cells (Figure 4E). By immunocytochemical staining, the differentiated embryonic germ layers were positive for MAP2 (ectodermal maker), NFL (ectodermal maker), cytokeratin (ectodermal maker), AFP (mesodermal maker), and ANP (endodermal maker) (Figure 4F-J).

\section{A}

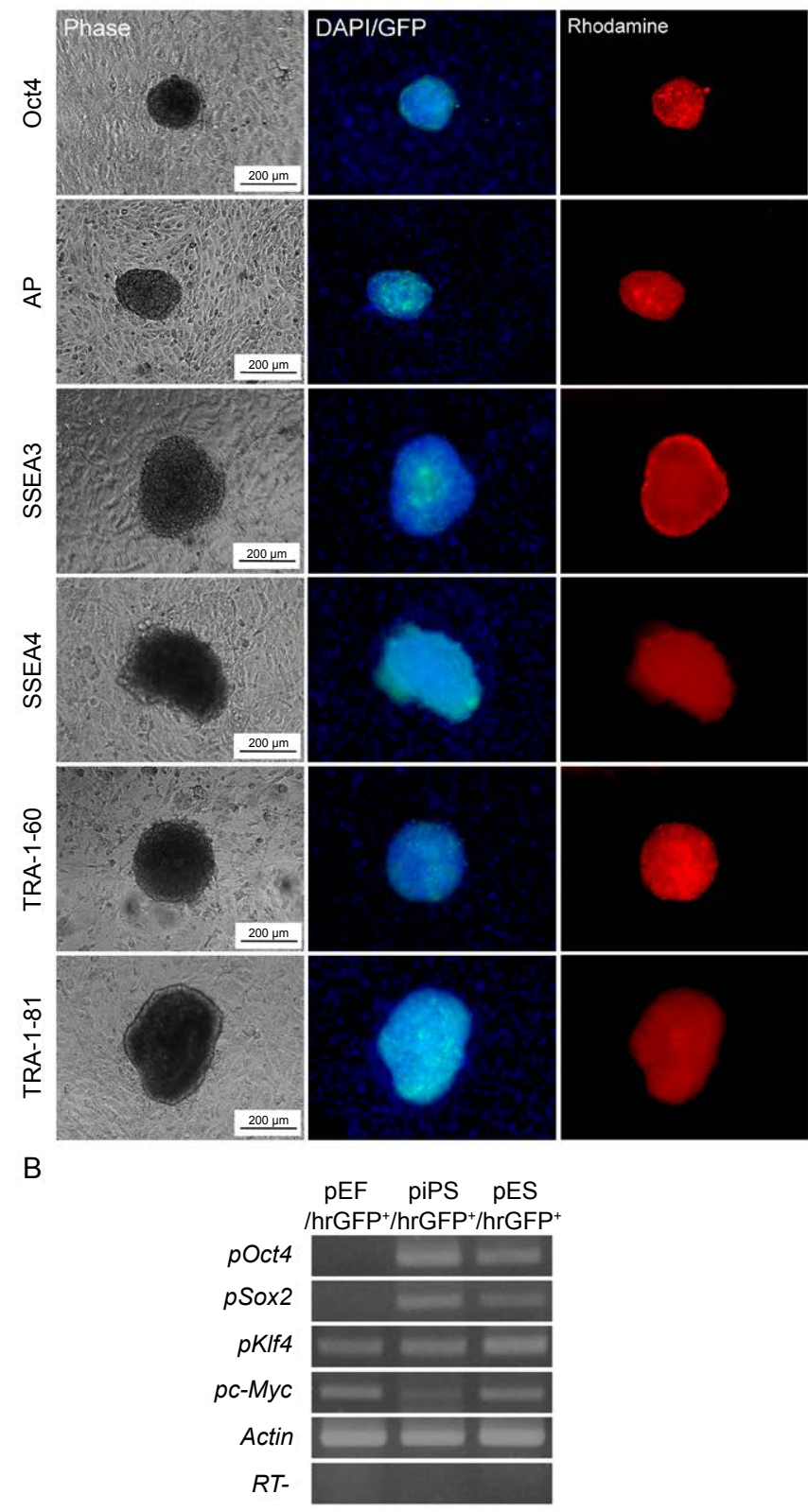

Figure 2: Expression of ES cell pluripotency markers in piPS/hrGFP+ cells. (A) Immunocytochemistry of piPS/hrGFP ${ }^{+}$cells with antibodies to Oct4, AP, SSEA-3, SSEA-4, TRA-1-60, and TRA-1-81. Nuclei were stained with DAPI (blue). (B) RT-PCR analysis of pluripotency genes. 


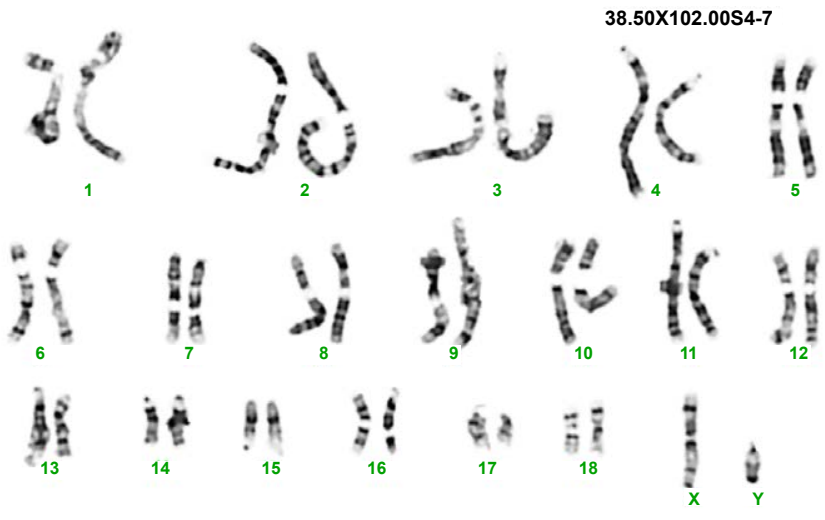

Figure 3: The normal karyotype of $36+\mathrm{XY}$ of piPS/hrGFP+ cells.

\section{Teratoma formation and in vivo tracking}

For determination of the in vivo differentiation capacity, the piPS/ $\mathrm{hrGFP}^{+}$cells were injected into immunocompromised mice. One month after transplantation, all NOD-SCID mice had developed small and solid teratomas of about $0.004 \mathrm{~cm}^{3}$ in size in dorsal flank. The teratomas grew and reached $0.55 \pm 0.21 \mathrm{~cm}^{3}$ in size three months after transplantation. The teratomas in the transplantation site were traceable by IVIS 50 through the 3-months experimental period. The relative intensity of fluorescent signal in ROI of treatment groups was $6.95 \pm 1.68$ folds higher than that of control groups three month after transplantation (Figure 5A). Thereafter, the NOD-SCID mice were sacrificed for histological and immunohistochemical analysis. The dissection of teratomas revealed various tissues derived from the three embryonic germ layers, including neural tissues (ectoderm), keratin pearls (ectoderm), skeletal muscle (mesoderm), smooth muscle (mesoderm), cardiac muscle (mesoderm), cartilage (mesoderm), adipose tissues (mesoderm), and glandular structures (endoderm) (Figures 5B and 5C).

\section{Discussion}

The iPS cells were first generated from murine differentiated somatic cells [2], and numerous follow-up researchers also successfully obtained iPS cells from human [14-16], monkey [17], rat [18], pig [1924], and horse [25]. The pig has been considered an optimal model for human biomedicine and research [3-5,9-11], Therefore the pig is a potentially useful model in regenerative medicine in human. In present study, the traceable hrGFP-expressing piPS cells were generated and have the potential for future application on regenerative and therapeutic medicine.

In the present study, we established the piPS/hrGFP ${ }^{+}$cells from reprogramming of hrGFP-expressing pEF cells. These novel piPS/hrGFP ${ }^{+}$cells generated in this study expressed hrGFP signal continuously and steadily for more than 90 passages. Expression of fluorescence can be detected in $\mathrm{pEF} / \mathrm{hrGFP}^{+}$cells and pass to piPS/ $\mathrm{hrGFP}^{+}$cells, EB and teratomas (Figure 1B, 1G, 4B, and 5A). They also possessed the typical defined characteristics of ES cells, including continuous proliferation with undifferentiated status, maintenance of a normal karyotype (Figure 3), and formation of EBs upon suspension culture (Figure $4 \mathrm{~A}$ and $4 \mathrm{~B}$ ). Expression of the ES cell markers including Oct-4, AP, SSEA-4, TRA-1-60, and TRA-1-81 were also detected in the undifferentiated piPS/GFP ${ }^{+}$cells, as $\mathrm{pES} / \mathrm{GFP}^{+}$cells we described previously [8]. Expression of endogenous pluripotency genes, pOct4,
pSox2, pKlf4, and $p c-M y c$, were detected in $\mathrm{piPS} / \mathrm{hrGFP}^{+}$and $\mathrm{pES} /$ hrGFP $^{+}$cells. In addition, significant $p K l f 4$ and $p c-M y c$ expression but not $p$ Oct4 and $p$ Sox 2 expression were detected in $\mathrm{pEF} / \mathrm{hrGFP}^{+}$ cells (Figure 2B). This phenomenon was also shown in the previous reports of Ezashi et al. (2009) [20] and Fujishiro et al. (2012) [21]. The endogenous Klf4 expression in human fetal endothelial cells was also reported previously, and these cells allowed to be reprogrammed with Oct4 and Sox2 [26]. These results imply that piPS cells might also be able to reprogram from porcine somatic fibroblasts by using transcription factors of Oct4 and Sox2 only.

The EB formation efficiency of piPS/hrGFP ${ }^{+}$cells in this study
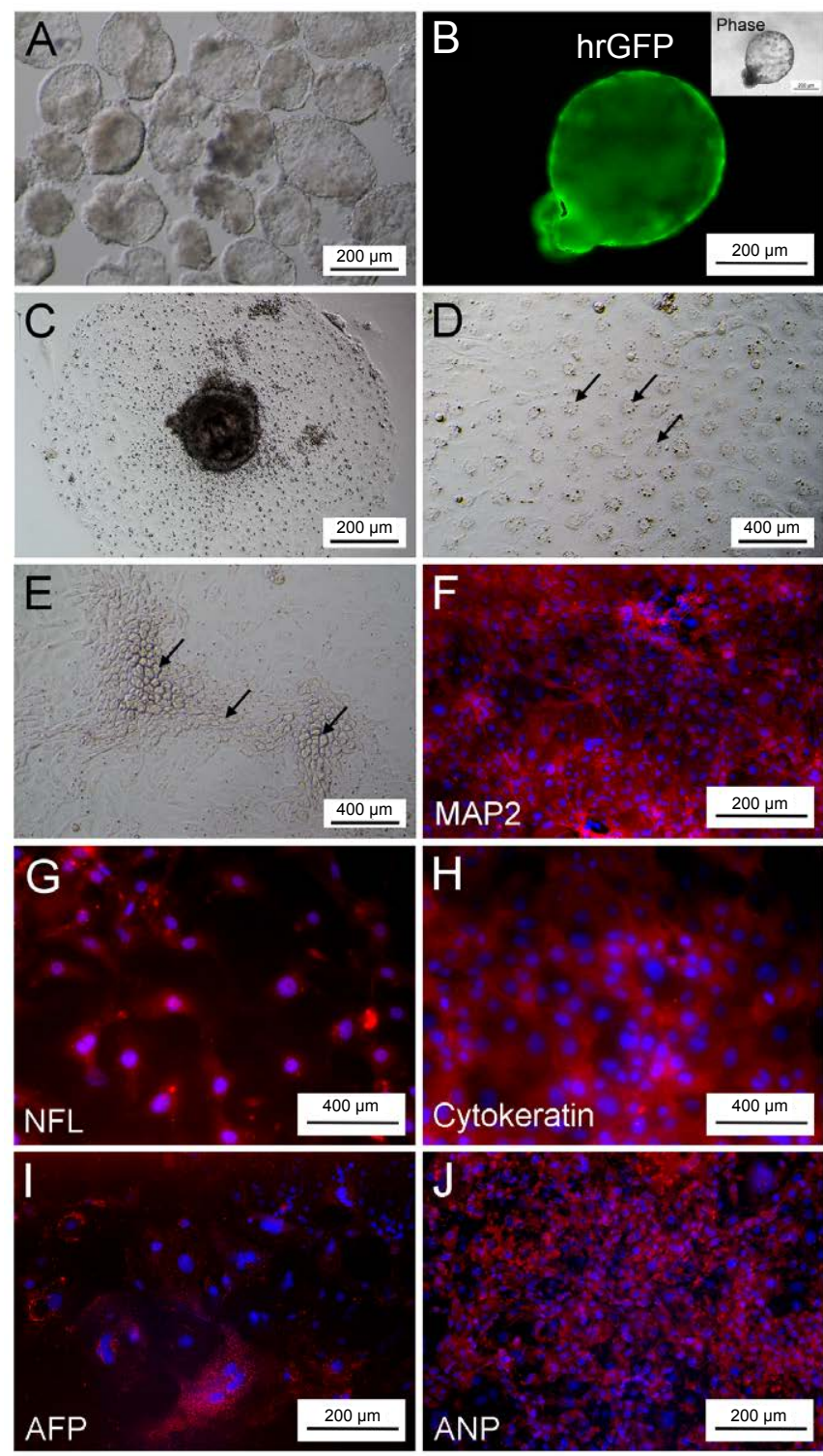

Figure 4: In vitro embryoid body formation and differentiation of piPS/hrGFP cells. (A) EB formation of piPS/hrGFP ${ }^{+}$cells on day 7 after hanging drop culture. (B) hrGFP expression of EB. (C) EB expansion after attachment to gelatin-coated surface of culture dishes. (D) The Nissl bodies of the cells derived from attached EB (Black arrows). (E) The epithelial cells derived from attached EB (Black arrows). Immunocytochemistry staining of cells derived from attached EB to against (F) MAP2, (G) NFL, (H) Cytokeratin, (I) AFP, and (J) ANP antibodies. Nuclei were stained with DAPI (blue). 
Citation: Liao YJ, Liao CH, Liao JW, Yuan K, Liu YZ, et al. (2014) Establishment and Characterization of Novel Porcine Induced Pluripotent Stem Cells Expressing hrGFP. J Stem Cell Res Ther 4: 208. doi:10.4172/2157-7633.1000208

A

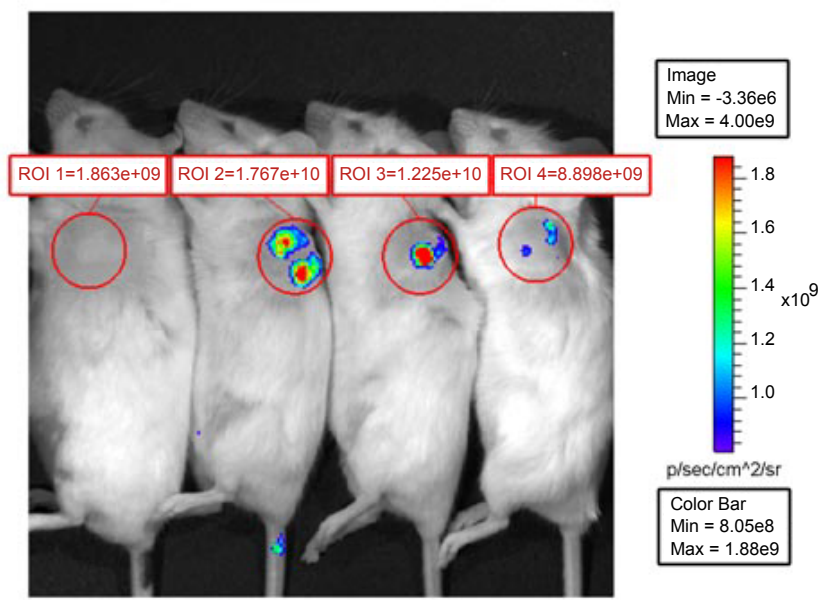

C

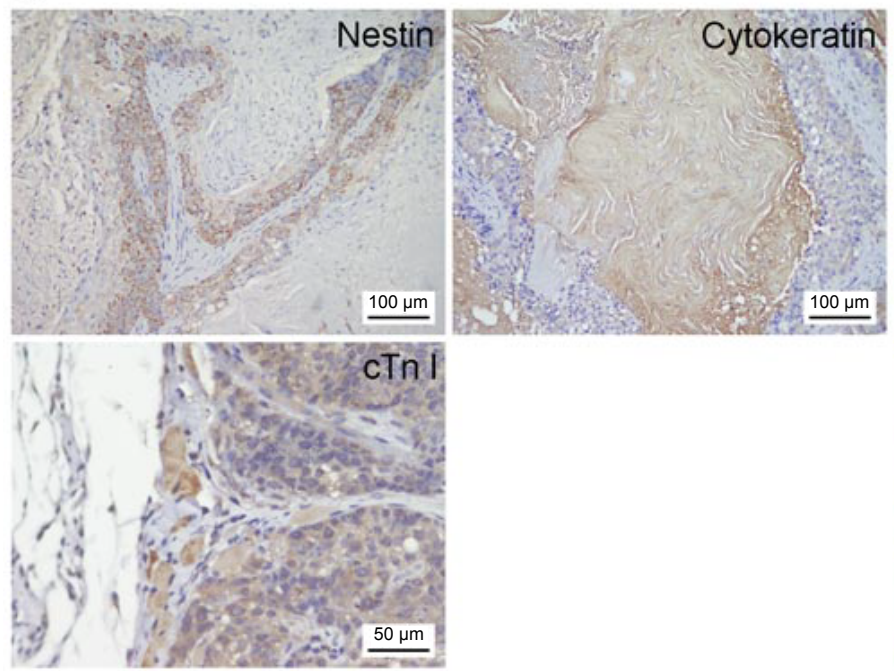

B
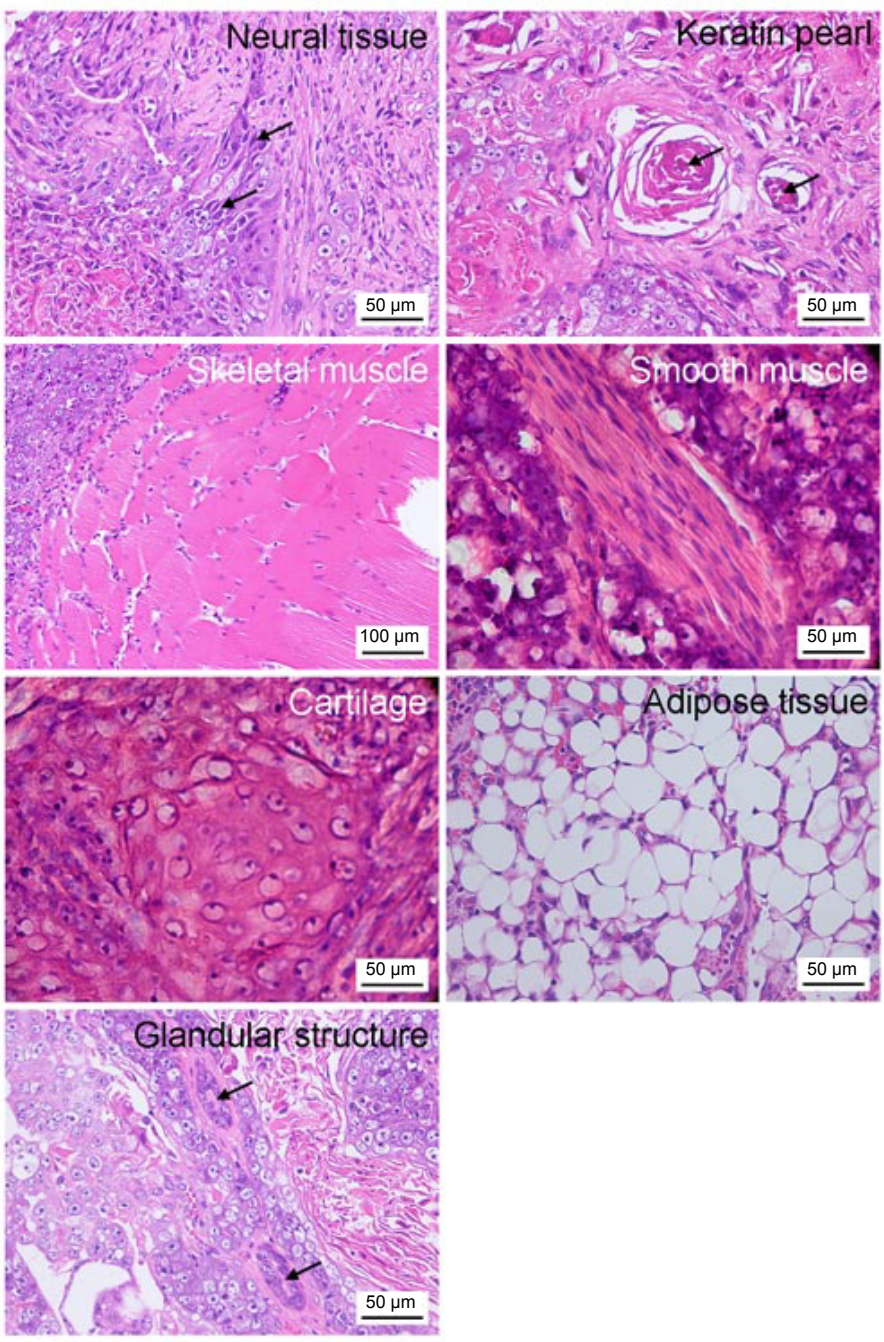

Figure 5: In vivo teratoma formation of piPS/hrGFP+ ${ }^{+}$cells. (A) Teratomas formation tracked by In Vivo Imaging System. (B) Hematoxylin and eosin staining of teratomas derived from piPS/hrGFP+ cells showed multiple tissues, including neural tissues, keratin pearls, skeletal muscle, smooth muscle, cartilage, adipose tissues, and glandular structures. (C) Immunohistochemical staining confirmed that piPS/hrGFP ${ }^{+}$cells differentiated into neural tissues, keratin pearl, and cardiac tissues in teratomas.

was high $(93.6 \pm 4.7 \%)$ and the differentiated cells derived from three embryonic germ layers were detected after adhesive culture of EB. These results demonstrated that the in vitro differentiation capacity of piPS/hrGFP ${ }^{+}$cells generated in this study. To our knowledge, there were few reports describing the success in teratomas induction by transplanting pES cells into the nude mice [27-29]. Hochereau-de Reviers and Perreau (1993) [28] reported that only the embryonic disc cells derived from days 10-11 but not days 5-6 blastocysts formed teratomas when transplanted into the nude mice. Similar observation had been depicted by Piedrahita et al. (1990) [29]. They failed to induce teratomas by pES cells derived from day 7-8 embryos. The difficulty in obtaining teratomas from the porcine embryonic cells of earlier stages was also confirmed by Anderson et al. (1994) [27], who demonstrated that teratoma can only be obtained by injecting pES cells isolated from blastocysts of day 11-12. However, in the present study, piPS/hrGFP ${ }^{+}$ cells formed teratomas after being transplanted into dorsal flank of NOD-SCID mice $(n=5)$. Other previous studies in the generation of pips cells also demonstrated the similar results [19-24]. The reason for teratomas formation of piPS cells after ectopic transplantation to SCID mice might result from different property of cells in epigenetic background via reprogramming process.

ES cells of ungulate species were rather difficult to establish from early embryos, but iPS cells provide a feasible approach for generating pluripotent stem cells. In our previous studies, transplantation of

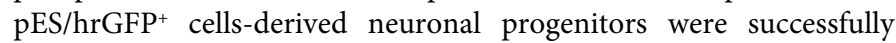
ameliorated the Parkinson' disease [9] and spinal cord injury [10] in the rat models. In addition, regeneration of periodontal furcation defects in a porcine model was improved by transplanted with $\mathrm{pES} / \mathrm{hrGFP}^{+}$ cells [11]. In the present study, piPS/hrGFP+ cells were established and possessed very similar property as $\mathrm{pES} / \mathrm{hrGFP}^{+}$cells we established previously [8]. In addition, the intensity of hrGFP signal in piPS/ $\mathrm{hrGFP}^{+}$cells was up to $6.95 \pm 1.68$ folds compared with control group. This will benefit the transplanted piPS/hrGFP ${ }^{+}$cells to easily locate, monitor and traced after transplantation. The therapeutic potential of $\mathrm{piPS} / \mathrm{hrGFP}^{+}$cells in regenerative medicine would be further 
Citation: Liao YJ, Liao CH, Liao JW, Yuan K, Liu YZ, et al. (2014) Establishment and Characterization of Novel Porcine Induced Pluripotent Stem Cells Expressing hrGFP. J Stem Cell Res Ther 4: 208. doi:10.4172/2157-7633.1000208

investigated to compare piPS cells and pES in biomedical applications. In a nutshell, these results implicate that traceable piPS/hrGFP ${ }^{+}$cells were successfully established and opened an avenue for biomedical application in pigs.

\section{Acknowledgements}

This work was supported by the grant 102AS-2.1.7-LI-L1 from Council of Agriculture, Executive Yuan, Taiwan.

\section{References}

1. Evans MJ, Kaufman MH (1981) Establishment in culture of pluripotential cells from mouse embryos. Nature 292(5819): 154-156.[PubMed]

2. Takahashi K, Yamanaka S (2006) Induction of pluripotent stem cells from mouse embryonic and adult fibroblast cultures by defined factors. Cell 126(4): 663-676.[PubMed]

3. Brandl U, Michel S, Erhardt M, Brenner P, Burdorf L, et al. (2007) Transgenic animals in experimental xenotransplantation models: Orthotopic heart transplantation in the pig-to-baboon model. Transplant Proc 39(2): 577-578. [PubMed]

4. Piedrahita JA, Mir B (2004) Cloning and transgenesis in mammals: Implications for xenotransplantation. Am J Transplant 4(6): 43-50.[PubMed]

5. Prather RS, Hawley RJ, Carter DB, Lai L, Greenstein JL (2003) Transgenic swine for biomedicine and agriculture. Theriogenology 59(1): 115-123. [PubMed]

6. Moore K, Piedrahita JA (1997) The effects of human leukemia inhibitory factor ( $\mathrm{hLIF}$ ) and culture medium on in vitro differentiation of cultured porcine inner cell mass (pICM). In Vitro Cell Dev Biol Anim 33(1): 62-71.[PubMed]

7. Brevini TAL, Antonini S, Cillo F, Crestan M, Gandolfi F (2007) Porcine embryonic stem cells: Facts, challenges and hopes. Theriogenology 68S: S206-S213.[PubMed]

8. Yang JR, Shiue YL, Liao CH, Lin SZ, Chen LR (2009) Establishment and characterization of novel porcine embryonic stem cell lines expressing hrGFP. Cloning Stem Cells 11(2): 235-244.[PubMed]

9. Yang JR, Liao CH, Pang CY, Huang LLH, Lin YT, et al. (2010) Directed differentiation into neural lineages and therapeutic potential of porcine embryonic stem cells in rat Parkinson's disease model. Cell Reprogram 12(4): 447-461.[PubMed]

10. Yang JR, Liao CH, Pang CY, Huang LLH, Chen YL, et al. (2013a) Transplantation of porcine embryonic stem cells and their derived neuronal progenitors in a spinal cord injury rat model. Cytotherapy 15(2): 201-208.[PubMed]

11. Yang JR, Hsu CW, Liao SC, Chen LR, Chen Yuan K (2013b) Transplantation of embryonic stem cells improves the regeneration of periodontal furcation defects in a porcine model. J Clin Periodontol 40(4): 364-371.[PubMed]

12. Chen LR, Shiue YL, Bertolini L, Merdrano JF, BonDurant RH, et al. (1999) Establishment of plurpotent cell lines from porcine preimplantation embryos. Theriogenology 52(2): 195-212.[PubMed]

13. Shiue YL, Liu JF, Shiau JW, Yang JR, Chen YH, et al. (2006) In vitro culture period but not passage number influences the capacity of chimera participation of inner cell mass and its deriving cells from porcine embryos. Anim Reprod Sci 93(1-2): 134-143.[PubMed]

14. Miller JD, Schlaeger TM (2011) Generation of induced pluripotent stem cell lines from human fibroblasts via retroviral gene transfer. Methods Mol Biol 767: 55-65.[PubMed]

15. Park IH, Zhao R, West JA, Yabuuchi A, Huo H, et al. (2008) Reprogramming of human somatic cells to pluripotency with defined factors. Nature 451(7175): 141-146.[PubMed]
16. Takahashi K, Tanabe K, Ohnuki M, Narita M, Ichisaka T, et al. (2007) Induction of pluripotent stem cells from adult human fibroblasts by defined factors. Cell 131(5): 861-872.[PubMed]

17. Liu H, Zhu F, Yong J, Zhang P, Hou P, et al. (2008) Generation of induced pluripotent stem cells from adult rhesus monkey fibroblasts. Cell Stem Cell 3(6): 587-590.[PubMed]

18. Liao J, Cui C, Chen S, Ren J, Chen J, et al. (2009) Generation of induced pluripotent stem cell lines from adult rat cells. Cell Stem Cell 4(1): 11-15 [PubMed]

19. Esteban MA, Xu J, Yang J, Peng M, Qin D, et al. (2009) Generation of induced pluripotent stem cell lines from tibetan miniature pig. J Biol Chem 284(26): 17634-17640.[PubMed]

20. Ezashi T, Telugu BP, Alexenko AP, Sachdev S, Sinha S, et al. (2009) Derivation of induced pluripotent stem cells from pig somatic cells. PNAS 106(27): 1099310998.[PubMed]

21. Fujishiro S, Nakano K, Mizukami Y, Azami T, Arai Y, et al. (2013) Generation of naive-like porcine induced pluripotent stem cells capable of contributing to embryonic and fetal development. Stem Cells Dev 22(3): 473-482.[PubMed]

22. Hall VJ, Kristensen M, Rasmussen MA, Ujhelly O, Dinnyés A, et al. (2012) Temporal repression of endogenous pluripotency genes during reprogramming of porcine induced pluripotent stem cells. Cell Reprogram 14(3): 204-216. [PubMed]

23. Montserrat N, Bahima EG, Batlle L, Häfner S, Rodrigues AM, et al. (2011) Generation of pig iPS cells: a model for cell therapy. J Cardiovasc Transl Res 4(2): 121-130.[PubMed]

24. Wu Z, Chen J, Ren J, Bao L, Liao J, et al. (2009) Generation of pig-induce pluripotent stem cells with a drug-inducible system. J Mol Cell Biol 1(1): 46-54. [PubMed]

25. Breton A, Sharma R, Diaz AC, Parham AG, Graham A, et al. (2013) Derivation and characterization of induced pluripotent stem cells from equine fibroblasts. Stem Cells Dev 22(4): 611-621.[PubMed]

26. Ho PJ, Yen ML, Lin JD, Chen LS, Hu HI, et al. (2010) Endogenous KLF4 expression in human fetal endothelial cells allows for reprogramming to pluripotency with just OCT3/4 and SOX2--brief report. Arterioscler Thromb Vasc Biol 30(10): 1905-1907.[PubMed]

27. Anderson GB, Choi SJ, Bondurant RH (1994) Survival of porcine inner cell masses in culture and after injection into blastocysts. Theriogenology 42(1): 204--212.[PubMed]

28. Hochereau-de Reviers MT, Perreau C (1993) In vitro culture of embryonic disc cells from porcine blastocysts. Reprod Nutr Dev 33: 475-483.[PubMed]

29. Piedrahita JA, Anderson GB, Bondurant RH (1990) On the isolation of embryonic stem cells: comparative behavior of murine, porcine and ovine embryos. Theriogenology 34(5): 879-901.[PubMed] 